\title{
A cooperação arriscada: a gênese do envio da Missão Venturini (1983) ao Suriname sob a lente da Teoria Prospectiva
}

\author{
The risky cooperation: the origins of the Missão Venturini (1983) to Suriname under the Prospect Theory
}

DOI: https://doi.org/10.22456/2178-8839.101585

Álvaro Vicente Costa Silva Universidade do Estado do Rio de Janeiro, Rio de Janeiro, Brasil alvarovicentecosta@gmail.com

\section{Resumo}

Este artigo analisa a motivação brasileira para agir como mediador de tensões em um dos momentos mais delicados da história do Suriname, em 1982: a crise que sucedeu o assassinato de diversos opositores de seu líder, Desiré Bouterse, que propugnava uma guinada na política externa de seu país, propondo uma aproximação de Cuba. A gestão brasileira ficou conhecida como “Missão Venturini”, enviada em 1983, cujo maior objetivo foi evitar essa guinada do governo surinamês, bem como potenciais ingerências dos Estados Unidos, que investiam em intensa campanha anticomunista sob o governo Ronald Reagan, na América do Sul. Nossa análise, pautada em documentos dos Arquivos Saraiva Guerreiro e Azeredo da Silveira, disponibilizados pelo CPDOC/FGV, usa a teoria prospectiva para oferecer uma resposta a tal indagação. Indicamos que a executiva de política externa, agindo de modo a evitar perdas decorrentes de possíveis gestões estadunidenses na região, optou pelo oferecimento de cooperação ao Suriname visando "moderar” o discurso e as ações do governo Bouterse.

Palavras-chave: Suriname; Teoria Prospectia; João Figueiredo.

\begin{abstract}
This paper analyse the Brazilian motivation to act as a mediator in one of the most difficult moments in Suriname's history, in 1982: the crisis that succeeded the killing of opponents of Desiré Bouterse's government, who advocated for a new path for the Surinamese foreign policy, including a convergence of positions with Cuba. The Brazilian intervention, known as "Missão Venturini”, sent in 1983 to Panamaribo, intended to avoid such Surinamese movement towards Cuba, and the potential American intervention that would follow such movement, as the Ronald Reagan government was intensely anti-communist. Our paper is based in declassified documents, disponible at CPDOC/FGV, and use the Prospect Theory in order to achieve our goal. We point to the Brazilian Foreign Policy Executive's risk-averse orientation. When facing the prospect of a "socialist" Suriname and the losses that an American intervention in South America would cause to Brazil, a cooperation offer seeking to contain Bouterse's actions and to avoid a Surinamese policy shift to the left seemed a less risky alternative.
\end{abstract}

Keywords: Suriname; João Figueiredo; Prospect theory. 


\section{Introdução}

O Suriname, país ao norte da América do Sul cuja população, em 1983, era de pouco mais de 365 mil pessoas (similar à população atual da cidade de Vitória, no Espírito Santo), conquistou sua independência dos Países Baixos em 1975. O pacto de independência (conhecido como golden handshake) com os neerlandeses configurou uma situação de dependência dos surinameses, que em seus primeiros anos ainda enxergavam os Países Baixos como ponto norteador de sua sociedade e política externa (JANSSEN, 2011). O Brasil, à época sob a presidência de Ernesto Geisel (1974-1979), reconheceu a independência surinamesa naquele ano. Posteriormente, o país também fez parte do Tratado de Cooperação Amazônica, firmado em 1978 (URT, 2010).

Cinco anos depois, ocorreu outro momento notável da nascente relação bilateral: a "Missão Venturini”, enviada pelo Brasil em 1983 a Paramaribo. A missão teve esse nome por ser chefiada por Danilo Venturini, chefe da Casa Militar naquela ocasião, agindo como enviado especial do presidente João Figueiredo (1979-1985). Ela ocorreu em meio ao acirramento da crise no país vizinho: o golpe ocorrido em 1982 se somava aos dois ocorridos em 1980, sendo que a repressão de Bouterse aos opositores foi brutal, com quinze mortos (HOEFTE, 2014). EUA e Países Baixos suspenderam a ajuda ao governo surinamês, que adotou uma inflexão retórica à esquerda, gerando notável preocupação no Brasil.

Este artigo visa a apontar as motivações que levaram o Brasil a enviar a Missão Venturini ao Suriname, entre 15 e 17 de abril de 1983. A pesquisa está baseada em fontes documentais disponíveis no CPDOC/FGV - especialmente os arquivos Azeredo da Silveira e Saraiva Guerreiro. Indicamos que a executiva de política externa brasileira seguiu uma ação arriscada - o oferecimento de cooperação para tentar "cooptar”, nos termos de Avila (2011), o governo surinamês, afastando-o de Cuba - em meio a expectativas de perdas ainda maiores com um Suriname "socialista".

Ainda que a tentativa de "cooptação" tenha sido arriscada - o governo Bouterse poderia seguir o curso de aproximação com Cuba, e o Brasil se indisporia com os EUA, que se prepararam para uma ação direta para destituir Bouterse -, foi tida como a melhor opção para se manter o status quo na região. Um cenário em que a América do Sul virasse foco do conflito Leste-Oeste, com ação direta dos EUA na fronteira amazônica, foi tida como um risco ainda maior ao grau de autonomia da política externa brasileira alcançado desde a adoção do Pragmatismo Responsável, no governo Ernesto Geisel (1974-1979).

Com isso, utilizaremos a teoria prospectiva para realizar a análise. Por ser uma teoria de escolhas sob risco, o trabalho de Kahneman e Tversky (1979) é adequado para alcançarmos respostas à nossa pergunta. Sua premissa básica é que indivíduos, ao lidar com prospecções de perdas (seja de bens tangíveis ou intangíveis), são mais tolerantes ao risco (e adotam alternativas arriscadas) do que quando lidam com prospecções de ganhos. A base de tal princípio é que indivíduos são mais afetados por perdas do que por ganhos, ainda que de valor idêntico, o que gera um apreço por alternativas que deem alguma possibilidade de manutenção do status quo.

De modo a responder nossa pergunta, além desta introdução, este artigo possui mais cinco seções. Na próxima seção, apresentaremos brevemente a Teoria Prospectiva, e as potencialidades de seu uso no campo da Análise de Política Externa. Na segunda seção, descreveremos o curso dos acontecimentos que culminou com o “massacre de 1982”, quando Desiré Bouterse assassinou diversos opositores, o estopim da crise surinamesa. Na terceira seção, analisaremos a reação brasileira, com as motivações da executiva de política externa para a escolha pelo oferecimento de "cooperação com firmeza" ao Suriname, que viria a ser a Missão Venturini. Na quarta, descreveremos o estilo e a forma da Missão Venturini, e a importância desses pontos para seu êxito parcial. Ao fim, realizaremos apontamentos gerais sobre nossa pesquisa. 


\section{A teoria prospectiva como alternativa para a análise de Política Externa}

A teoria prospectiva é uma teoria de decisão sob situações de risco. Elaborada por Daniel Kahneman e Amos Tversky (1979), sua principal premissa é que indivíduos tomam decisões não só com base no outcome esperado da alternativa escolhida, mas nas consequências dessa escolha em relação a um ponto de referência pré-determinado.

Em tal panorama, pessoas são avessas ao risco em meio a expectativas de ganho, mas tolerantes a ele quando lidam com expectativas de perda. Ou seja, se arriscam mais de modo a evitar uma perda, seja em bens materiais ou imateriais, mesmo que sob risco de agravar essa perda (KAHNEMAN; TVERSKY, 1979, JERVIS, 1994). Essa assimetria de esforços é causada pelo chamado endowment effect: uma pessoa valoriza mais o que ela já possui do que aquilo que ela ainda não possui, o que gera uma supervalorização do bem aos olhos da pessoa que o detém (LEVY, 1994).

Mas qual é o ponto de referência que serve de baliza ao indivíduo para medir as expectativas de perda/ganho? Geralmente é considerado o status quo, uma vez que há uma tendência humana em optar por alternativas que prezem por tal estado de coisas (SAMUELSON; ZECKHAUSER, 1988; LEVY, 1994; JERVIS, 1994). Se a posição do policymaker está se deteriorando em relação ao status quo, ele está em domínio de perda; se a expectativa é de melhora, está em domínio de ganho (MERCER, 2005). Desse modo, o fator mais importante na tomada de decisão do indivíduo é o enquadramento da questão, como sendo de ganho ou de perda. Isso é o que Kahneman e Tversky (1979) denominaram framing (enquadramento). Ele é a concepção que o policymaker tem de atos, outcomes e contingências ligadas a uma escolha (BOETTCHER, 2004).

Há um consenso sobre a potencialidade do uso da teoria prospectiva para explicar eventos nas relações internacionais (LEVY, 1994; JERVIS, 1994; BEREJIKIAN, 2002; MERCER, 2005; MCDERMOTT; FOWLER; SMIRNOV, 2008). Diversos trabalhos, inclusive, já a aplicaram para analisar processos de tomada de decisão (FARNHAM, 1994; MCDERMOTT, 1994; HAAS, 2001). Originalmente, a teoria prospectiva foi concebida como uma teoria de tomada de decisão individual. Por isso, uma crítica comumente recebida era da dificuldade de se traduzir tal teoria para decisões de política externa, geralmente tomadas em grupo, em forma de uma executiva de política externa (LEVY, 1997; BOETTCHER, 2004).

Entretanto, estudos mais recentes apontam que o "problema de agregação" não viola os resultados esperados pela teoria prospectiva - na realidade, os mesmos padrões de decisão seriam verificados também em grupos (VIS, 2011). Uma aplicação exitosa da teoria prospectiva para decisões em grupo é o estudo de Schenoni, Braniff e Battaglino (2020) sobre a tomada de decisão dos militares argentinos que culminou na Guerra das Malvinas, em 1982. Com isso, nosso artigo visa contribuir ao debate ao aplicar a teoria prospectiva para a decisão da executiva de política externa brasileira em a Missão Venturini ao Suriname.

\section{Suriname: da independência à crise}

No golden handshake, que garantiu a independência surinamesa, foi acordado um apoio neerlandês à ex -colônia durante um período de 10-15 anos. O processo de independência tinha problemas: foi mais incentivado pelos Países Baixos do que pelo povo local; e a população hindu do Suriname, temendo a maioria de crioulos, eram contrários (LAMPREIA, 2010). Clamores para que tal ação fosse decidida em plebiscito foram ignoradas, e a aprovação do processo foi apertada. Para agravar a situação, o êxodo para os Países Baixos ocorria em grande número na época (HOEFTE, 2014). Com a independência firmada, foram abertas embaixadas em Haia, Washington, Cidade do México, Brasília e Bruxelas, ao passo que Holanda, Indonésia, Guiana, Venezuela, Coréia do Sul, Estados Unidos, França e Brasil abriram embaixadas no país (CAVLAK, 2016).

O Suriname tinha duas particularidades: multiplicidade étnica e a dependência econômica vinda da extração de bauxita. Sobre o primeiro ponto, haveria maior sentimento, entre diversos setores da população, de pertencimento a um 
grupo racial do que à identidade surinamesa, gerando certa instabilidade na convivência dessas etnias (URT, 2010). Sobre o segundo ponto, boa parte da economia do país dependia da extração de bauxita, apesar do potencial para silvicultura e colheita - o Suriname ainda precisava importar comida, por exemplo (JANSSEN, 2011).

Nesse contexto, em 1980, o país passou por dois golpes militares (o primeiro, exitoso; o segundo não), ambos motivados por questões entre governo e militares, sem um caráter ideológico - reclamações salariais, por exemplo, foram um motivador (URT, 2010). Após o primeiro, foi instaurado um Conselho Nacional Militar que, em tese, supervisionaria o novo primeiro-ministro, Chin-A-Sen. Na prática, entretanto, esse Conselho virou o centro do poder político nacional, sendo Desiré Boutersé o seu membro mais relevante - e desde 1980 os militares decretaram estado de emergência no país (AVILA, 2011).

Os militares surinameses consideravam-se "revolucionários” e eram próximos de ideólogos à esquerda do espectro político. Bouterse, preocupado em manter seu poder, investiu na necessidade de uma ideologia movendo o governo - assim, apostou em uma guinada à esquerda, para que seu discurso acompanhasse o dos demais militares (HOEFTE, 2014). Isso fomentou discordâncias com setores moderados do governo, inclusive o primeiro-ministro Chin-ASen, que foi derrubado do cargo em fevereiro de 1982 - tentativas de contragolpe e a pressão de setores democráticos foram insuficientes para impedir a progressiva radicalização do regime (JANSSEN, 2011).

Pouco após a saída de Chin-a-Sen, ainda no primeiro semestre de 1982, Bouterse chegou a visitar uma conferência da Internacional Socialista, realizada em Granada (do governante Maurice Bishop, que também geria um governo à esquerda), e de lá realizou uma viagem para Cuba, de modo a encontrar o líder da ilha, Fidel Castro (JANSSEN, 2011). A aproximação com Cuba foi recíproca. A indicação cubana do embaixador Osvaldo Cárdenas para o país, anteriormente diretor do departamento do Partido Comunista para o Caribe a América Central, foi um indicador da importância que os cubanos davam ao Suriname (JANSSEN, 2011).

Além do líder cubano, outra inspiração era a Granada de Maurice Bishop. O país passou a ser tido como modelo para Bouterse, e essa admiração gerou um convite para o granadino visitar o país sul-americano. Entretanto, a visita de Bishop foi ofuscada por diversos protestos populares, reclamando da escalada autoritária, da continuidade do estado de emergência instaurado em 1980 e demandando eleições abertas - Bouterse rejeitava a ideia de democracia constitucional, propondo apenas a de democracia popular (AVILA, 2011).

Foi o limite para Bouterse. Em abril de 1982, o militar surinamês já havia suprimido uma tentativa de golpe liderado por Wilfried Hawker, militar dissidente e insatisfeito com a guinada ideológica do país, que acabou fuzilado (URT, 2010). Após os protestos em meio à visita do líder granadino, as possibilidades de reconciliação entre militares e sociedade acabaram. Em 7 de dezembro de 1982, Bouterse ataca sedes de rádios e jornais, e 15 opositores do governo foram executados, consolidando o clima de medo e tensão entre os surinameses, além de uma onda migratória para os Países Baixos e os EUA. (HOEFTE, 2014)

Desse modo, o Suriname (e sua instabilidade interna, bem como sua guinada em política externa) começava a ser uma fonte de preocupação para os Estados Unidos no hemisfério. Naquele momento, Ronald Reagan gestava uma política de reavivamento da Guerra Fria, prometida em sua vitoriosa campanha à Presidência dos EUA, calcada em forte retórica anticomunista, ao longo de 1980 (MCMAHON, 2003). Seria inaceitável ao governo estadunidense mais um foco de desafio à sua hegemonia no continente americano.

O massacre de dezembro de 1982 foi o limite. Em meio à reação condenatória da comunidade internacional, tanto os Estados Unidos quanto os Países Baixos congelaram o fornecimento de ajuda ao governo Bouterse. Os neerlandeses justificaram a suspensão de auxílio econômico, cultural e militar afirmando que tal auxílio não poderia servir como apoio para governos repressivos (JANSSEN, 2011). De igual modo, os EUA também suspenderam a provisão de auxílios ao Suriname. 
Os impactos da suspensão da ajuda agravaram a situação da frágil economia surinamesa. No início da década de 1980, metade da população era composta por classes populares. A crise do consumo afetou a classe média, reduzindo o acesso dessas pessoas aos aparelhos estatais de serviço social e gerando queda na qualidade de vida - para muitas famílias, as remessas de dinheiro vindas de parentes emigrados eram cruciais para sobreviver à crise (HOEFTE, 2014).

\section{A Missão Venturini e a Teoria Prospectiva: evitando o risco maior}

O isolamento diplomático e o agravamento da crise surinamesa, decorrentes do congelamento de ajuda financeira dos Países Baixos e dos EUA, causavam preocupação na executiva de política externa brasileira. Identificamos como membros dessa executiva: o Presidente João Figueiredo; o chanceler Ramiro Saraiva Guerreiro; o chefe do Serviço Nacional de Informações, Octávio Aguiar de Medeiros; e o chefe da Casa Militar, Danilo Venturini. O embaixador brasileiro em Paramaribo, Luiz Felipe Lampreia, apesar de não integrar a executiva, teve notável papel de influência ao provê-la de informações sobre os acontecimentos no Suriname.

A consideração era de que a posição brasileira na América do Sul estava em risco de declínio, por quatro razões: 1) o Suriname poderia instaurar um regime aos moldes cubanos na fronteira amazônica, despertando antigos temores sobre a integridade nacional; 2) os EUA ameaçaram intervir na questão, o que dobrou as preocupações sobre os impactos na fronteira amazônica e sobre o grau de autonomia da inserção brasileira no sistema internacional; 3) com isso, o Suriname ameaçava colocar a América do Sul no foco da contradição Leste-Oeste, diminuindo a margem de manobra da política externa brasileira no sistema internacional; 4) a questão poderia dificultar o rumo da transição democrática, reativando setores mais duros das Forças Armadas. Vamos avaliar cada uma delas em maior detalhe.

A maior preocupação era de uma intervenção brasileira não exitosa. Isso passaria especialmente pela possibilidade de Bouterse não recuar de sua aproximação com o bloco soviético, ou pela possibilidade de uma irritação dos EUA em meio à intercessão brasileira. A mistura de ambas possibilidades era o pior cenário possível. Assim, a estratégia brasileira, conforme classificada por Avila (2011), foi a de “cooptar” o Suriname, de modo a afastá-lo da influência cubana e de manter um canal aberto do país com o Ocidente. Isso se deu pelo uso da cooperação, mas com sinais inequívocos de firmeza. Assim, o Brasil demonstraria que, apesar da busca por uma solução cooperativa, não haveria tolerância à “cubanização” de um país fronteiriço.

A ideia da "cubanização" do Suriname era uma possibilidade aventada pela executiva de política externa brasileira. A embaixada brasileira em Paramaribo identificou a crescente personificação na figura de Bouterse, com a percepção de que, acima de inclinações ideológicas, ele agia de modo a garantir seu poder, instrumentalizando grupos ideológicos a seu favor (BRASIL, 1983e). Assim, o PALU ${ }^{1}$, partido da base aliada, serviria para dar ao líder surinamês uma base ideológica bem quista em setores mais populares (BRASIL, 1983b). Havia também a percepção de que Bouterse possuía "mania de perseguição que chegaria à paranoia”, e que estava pessoalmente envolvido nas mortes de opositores em 1982 (BRASIL, 1983b). Segundo impressões angariadas pela Embaixada do Brasil em Haia, uma inflexão na posição de "um ou dois líderes importantes” poderia gerar grande mudança no curso de eventos da crise do Suriname, por se tratar de um país pequeno (BRASIL, 1982b).

Em mensagem para a população surinamesa no Natal de 1982, pouco após o assassinato de opositores, Bouterse realçou a intenção de "buscar auxílio onde quer que fosse", e que as condições externas determinariam o que ocorreria no ambiente interno do Suriname (BRASIL, 1983b). A preocupação aumentou em meio ao posicionamento dos meios de comunicação soviéticos e cubanos: Demonstraram uma posição de complacência com o regime de Bouterse (BRASIL,

\footnotetext{
1 “Progressieve Arbeiders en Landbowers Unie” (União Progressista dos Trabalhadores e Agricultores, em tradução do autor), partido radical de esquerda.
} 
1983b). Entretanto, o líder militar mencionou que a ajuda holandesa poderia ser substituída por uma de um "grande país sul-americano" - o que o Itamaraty interpretou como uma abertura ao Brasil (BRASIL, 1983b).

Em janeiro de 1983, o Suriname acenou com o envio de uma missão a Brasília, de modo a apontar os rumos que o país tomaria em meio à crise, além de pedir auxílio econômico, em meio à suspensão da ajuda neerlandesa e estadunidense (BRASIL, 1983a). O chanceler brasileiro também conjecturou que tal aceno seria ligado a uma entrevista por ele concedida dias antes. Perguntado sobre a crise surinamesa, Guerreiro afirmou que era "problema interno" daquele país, e que o Brasil “não se coloca em posição de juiz ou professor”, ainda que esperasse que o Suriname não virasse um foco da confrontação Leste-Oeste ou de risco à segurança brasileira, algo que “o Brasil jamais tolerará” (BRASIL, 1983a).

A possibilidade da “cubanização” também foi apontada pelo embaixador Luiz Felipe Lampreia. Ele relatou que a embaixada cubana no país estava "sempre com as janelas abertas, como para convidar a observação de que lá só ocorre uma atividade preguiçosa e escassa”, mas o embaixador cubano no país tinha “trânsito excepcional” na cúpula do regime, sendo "figura lendária no microuniverso surinamense" (BRASIL, 1983f). Entretanto, Cuba ainda não havia avançado em prestação de assistência técnica ao Suriname: sua influência era mais notada na mídia, controlada pelo governo: documentários cubanos, além de material vietnamita e nicaraguense, eram constantes (BRASIL, 1983f).

Lampreia afirma que a língua e o temor de desafiar demais o governo de Ronald Reagan eram as principais barreiras para uma ação mais incisiva de Cuba. Assim, o país optou por "utilizar simpatizantes de peso para capturar a imaginação de um Bouterse disponível e ameaçado”, para oferecer-lhe ajuda e, gradualmente, criar condições para se implantar "tão sólido quanto possível [um] regime ao gosto de Cuba” no Suriname (BRASIL, 1983f). Desse modo, Lampreia foi taxativo: "Cuba está desenvolvendo aqui uma estratégia original e tentativa que visa a induzir, cirurgicamente, o Suriname a se transformar em República Popular” (BRASIL, 1983f).

Os EUA, ao contrário, tinham um plano de ação incisivo para lidar com a situação. O Brasil foi “convidado” por William P. Clark, assessor de Reagan para a segurança nacional, a invadir o Suriname. A ideia era destituir Bouterse de seu cargo. Houve uma reunião entre Clark, Figueiredo, Octávio Aguiar de Medeiros e Danilo Venturini, em que o presidente declina o convite, argumentando que "tratando-se de um país vizinho, [...] uma reação adequada e exclusivamente brasileira” seria tomada (LAMPREIA, 2010, p. 110). A solução “adequada e brasileira” almejava evitar ingerências dos EUA na região, que incidiriam negativamente na margem de autonomia de ação do Brasil. Entretanto, os EUA concederam um prazo de "dois ou três meses” e, caso o Brasil não fosse exitoso, os estadunidenses entrariam em cena - já havia, inclusive, um plano elaborado pelos EUA, com alvos definidos a serem atacados por brasileiros e americanos (LAMPREIA, 2010, p. 110-111).

O Brasil, naquele momento, investia na busca por mais autonomia à sua política externa, respondendo às demandas de um país que visava superar a condição de vulnerabilidade econômica por meio do desenvolvimento de seu parque industrial. Esse processo foi iniciado no governo Ernesto Geisel (1974-1979), com o Pragmatismo Responsável. Nele, o Brasil aprofundou a diversificação de suas parcerias externas, flexibilizando restrições ideológicas, de modo a explorar novos mercados aos produtos brasileiros. A ênfase na África Negra (com o reconhecimento da independência angolana, do MPLA $^{2}$ ), a retomada de relações com a China Popular, e as demonstrações de maior autonomia frente aos EUA (como o Acordo Nuclear assinado com a Alemanha em 1975) foram alguns elementos que marcaram a adoção do "pragmatismo" no ambiente internacional (PINHEIRO, 2013; SARAIVA, 1998).

Esse tom foi mantido no governo Figueiredo, na política externa Universalista. Apesar das crescentes restrições vindas do cenário internacional, como o segundo choque do petróleo, a alta dos juros e o protecionismo dos países desenvolvidos, a base herdada do Pragmatismo Responsável foi mantida. Além de pequenas mudanças na linguagem e estilo, uma mudança notável foi justamente na política para a América do Sul. Isso gerou ânsia pela recuperação da identidade "latino-americana" da política externa, busca por reforço do intercâmbio comercial com os vizinhos, e política

\footnotetext{
${ }^{2}$ Movimento Popular de Libertação de Angola
} 
para se evitar intervenções externas na região (LIMA; MOURA, 1982). Essa política, cujo ápice foi a superação da rivalidade regional com a Argentina, marcou a "latinoamericanização" da política externa brasileira (SARAIVA, 2012).

Nesse contexto, um Suriname que flertava com uma guinada ao socialismo; somada ao risco de os EUA, sob a política de reavivamento da Guerra Fria, realizarem uma intervenção na América do Sul, em plena fronteira amazônica, comprometeria a linha de ação adotada pelo Brasil desde 1974. Uma ingerência estadunidense atrapalharia os planos brasileiros de consolidação de uma posição mais autônoma no sistema internacional, bem como uma posição de preponderância regional. Vale lembrar que, no governo Geisel, o Brasil arquitetou o Tratado de Cooperação Amazônica, visando fortalecer sua posição na região e facilitar a penetração econômica brasileira nos países da Bacia, inclusive de modo a dirimir efeitos de "projetos concorrentes", como o Pacto Andino (BRASIL, 1976). Uma presença estadunidense minaria tais esforços brasileiros para estabelecer uma posição de preponderância e influência na região.

A América do Sul trazida ao epicentro da contradição Leste-Oeste inviabilizaria não apenas as condições externas para se gerir a estratégia de inserção universalista, como também poderia minar as condições internas para tal. Críticas domésticas eram cada vez mais latentes ao Universalismo, inclusive entre alguns diplomatas (FERREIRA, 2009). Uma realidade de contradição Leste-Oeste na região engrossaria o coro dos favoráveis ao retorno a uma política externa de maior alinhamento aos Estados Unidos.

Por fim, outro risco, ainda que menor, era ligado às consequências de um Suriname "socialista” ao processo de redemocratização brasileira. Azeredo da Silveira, embaixador em Washington, advertiu sobre essa situação: "o surgimento de algum tipo de guerrilha, por menor que seja, numa região vasta como a Amazônia” (BRASIL, 1983c). Tal situação acirraria os ânimos de opositores do governo militar e tumultuaria a transição "lenta, gradual e tranquila" rumo a democratização. Assim, Saraiva Guerreiro, em meio ao panorama de isolamento surinamês, confidenciou para Silveira o que acreditava ser a melhor solução para a questão (que o Brasil, posteriormente, viria a seguir): uma aproximação e presença dos países opostos à influência cubana no Suriname, via cooperação (técnica, econômica ou outras), prevenindo uma predominância de Cuba e URSS sobre o governo Bouterse (BRASIL, 1983d).

$\mathrm{Na}$ conversa com o assessor de Reagan, a apresentação de um contraponto à ideia da invasão (a solução cooperativa) foi aventada por Octávio Medeiros (LAMPREIA, 2010). Essa solução e a posição oficial do Brasil foi confirmada na reunião da executiva de política externa incumbida de decidir a melhor alternativa de ação. A entrevista envolveu Figueiredo, Octávio Medeiros, Danilo Venturini e Saraiva Guerreiro. O chanceler lembrou que Bouterse citava Cuba, mas também os demais latino-americanos em seus discursos. O que o Brasil daria ao país era "uma nova porta para o exterior", evitando dar para Cuba “o monopólio dos contatos externos do Suriname”, pois Guerreiro não via Bouterse deixando o poder tão cedo (GUERREIRO [1985], 2019, p. 508-509).

Assim, o conteúdo da ação brasileira foi levantado por Octávio Medeiros, mas convergia com a posição mantida pelo Ministério de Relações Exteriores desde o início da crise. O oferecimento de cooperação para evitar um isolamento diplomático do Suriname (e uma consequente aproximação de Cuba) era exatamente o que Saraiva Guerreiro defendeu como melhor modo de agir para lidar com a questão. Em setembro de 1982, meses após a queda de Chin-A-Sen e pouco após uma visita à Paramaribo, o chanceler brasileiro apontou que a "fluidez" e "indeterminação ideológica" do Suriname demandavam que o Brasil se apresentasse como opção para cooperação e entendimento, algo que seria mais latente em meio a "existência, na base militar surinamense, de setores de orientação mais radical e favoráveis à aproximação com Cuba, Granada e Nicarágua” (BRASIL, 1982a).

Apesar disso, o presidente Figueiredo se manteve reticente em relação ao aprofundamento da cooperação naquele momento, considerando a condição de dificuldades econômicas do Brasil. Houve mudança de postura em meio a intensificação da crise surinamesa meses depois, especialmente com o massacre de dezembro, em que a necessidade de intervir pareceu mais latente. Daí, a ideia da cooperação. Se o conteúdo da ação, ainda que sugerido por Octávio Medeiros, 
tenha sido ponto de defesa do chanceler Saraiva Guerreiro, a forma e o estilo sofreram influência maior dos outros integrantes da executiva de política externa, conforme veremos a seguir.

\section{O envio da Missão: cooperação e firmeza}

Em meio à definição da solução cooperativa, a maior preocupação da executiva de política externa era em modos de demonstrar para Bouterse que o Brasil, apesar de optar por uma solução cooperativa, estava disposto a ser firme para evitar a guinada à esquerda do Suriname. Essa preocupação ultrapassava, inclusive, a executiva de política externa brasileira. Ronald Reagan temia o modo que governo surinamês interpretaria a Missão Venturini, que prezava pela cooperação e não-isolamento para evitar uma guinada pró-Cuba do Suriname.

O presidente dos EUA, em carta enviada ao presidente Figueiredo, esperava que o posicionamento do Brasil não fosse compreendido como uma forma de apoio ao regime surinamês, e esperando um auxílio "in the common aim of preventing cuban expansion in South America while carrying out your effective foreign policy”3. A resposta do mandatário brasileiro frisou a importância da compreensão estadunidense ao respeito do princípio de não-intervenção em assuntos dos países vizinhos, especialmente no que seria um momento de instabilidades institucionais na região. Além disso, foi ressaltada a condição do Suriname como país vizinho e a preocupação nacional com o desenrolar dos acontecimentos do governo Bouterse (BRASIL, 1983h).

Assim, a escolha de Venturini por parte de João Figueiredo seguiu um ponto pragmático. O militar escolhido conversou com o chanceler Guerreiro “até sobre o linguajar que deveria utilizar lá”. (GUERREIRO, 2019 [1985], p. 507). João Urt (2010) afirma que a escolha de Venturini enviaria uma mensagem aos cubanos. Entretanto, deve-se considerar que a mensagem principal era ao próprio Bouterse: Como Venturini era chefe do Gabinete Militar e enviado especial do Presidente brasileiro, a sinalização era de que o tema era de suma importância ao Brasil. Além disso, conforme narra Lampreia

[...] Venturini chegou a Paramaribo a bordo do avião presidencial. Houve então uma cena de anedota: abriu-se a porta da aeronave e saltaram vinte agentes de segurança, com óculos escuros enormes e volumes conspícuos à cintura, formando uma ala paralela à escada do avião. Só então o general desceu. Era uma demonstração de força estranha para quem desembarcava atrás de um entendimento pacífico. (LAMPREIA, 2010, p. 111-112)

Desse modo, nota-se a preocupação da missão brasileira em demonstrar que havia o oferecimento de cooperação e uma tentativa de não isolar os surinameses. Entretanto, até por conta do temor estadunidense com o modo em que isso seria interpretado pelo governo Bouterse, o Brasil realizou a operação de modo a deixar claro que demandaria uma posição diferente do Suriname e de que aquele apoio não era uma complacência com as guinadas à esquerda de seu governo. Assim, novamente segundo Lampreia,

Descrevi-os como oportunistas que recebiam o apoio cubano porque era o único disponível. Ponderei que, se eles fossem convencidos, primeiro, de que iam ser atacados e, segundo, de que poderiam conseguir benefícios, acabariam por aceitar uma aproximação com o Brasil.

Venturini foi muito hábil. Teve uma conversa de horas com Bouterse - em que fui o intérprete - ao longo de dois dias seguidos, mas não exigiu nada, ressaltando apenas que não era desejável transpor a Guerra Fria para a América do Sul. Foi uma forma cifrada de dizer que o Brasil não poderia aceitar a implantação da influência cubana no Suriname. (LAMPREIA, 2010, p.112)

Desse modo, a forma que a ação ocorreria não foi definida exclusivamente pelo Itamaraty. A escolha de Venturini por Figueiredo pressupunha uma mensagem de ação clara e livre de interpretações dúbias, que fosse suficiente para

\footnotetext{
3 “No objetivo comum de prevenir a expansão cubana na América do Sul enquanto empreende sua eficaz política externa” (BRASIL, 1983g, tradução do autor).
} 
desarmar quaisquer pretensões de Bouterse utilizar a preocupação brasileira em um jogo de barganha junto aos cubanos para angariar mais poder.

O Brasil proveu material e treinamento militar, bolsas de estudos universitárias, treinamento diplomático de surinameses no Instituto Rio Branco, importação de produtos como o arroz surinamês, e outros tipos de cooperação técnica (BRASIL, 1983k). Além disso, proveu assistência à missão surinamesa, que pediu empréstimos ao sistema financeiro internacional, buscando também flexibilizar a posição “pouco receptiva” dos EUA a tais investidas (BRASIL, 1983j).

Sobre os resultados, pode-se dizer que houve um êxito parcial. A Missão Venturini conseguiu reforçar a “alternativa brasileira” para Bouterse, o que evitou um isolamento surinamense. Entretanto, conforme aponta Avila (2011), o país manteve relações com Cuba até a invasão estadunidense a Granada, em outubro de 1983 - sendo o impulso para o governo surinamês rebaixar o nível das relações com o governo de Fidel Castro. Bouterse tentava sinalizar uma posição de gradual desengajamento ideológico com Cuba, ainda que tentando explorar possíveis benefícios desse relacionamento. Um exemplo foi o envio de uma missão surinamesa a Cuba, em maio de 1983, buscando meios de se obter cooperação militar, mas o chefe dessa missão, entretanto, era um oficial "sem ideologia ou simpatias cubanas”, o que foi tido pelo Itamaraty como "altamente significativo" do gradual desengajamento surinamês (BRASIL, 1983i).

\section{Conclusão}

Neste artigo, lançamos mão de fontes documentais de modo a reconstituir o processo decisório que culminou no envio da Missão Venturini ao Suriname. Apontamos que a executiva de política externa agiu conforme os preceitos da Teoria Prospectiva, em que abraçou uma alternativa de ação arriscada em meio a uma expectativa de perdas potenciais com a "guinada socialista” do Suriname. A escolha por uma abordagem cooperativa não tinha segurança de resultado não era sabido se Bouterse interpretaria a ação como um sinal de complacência com ações que a executiva de política externa brasileira julgava intoleráveis - e ameaçou indispor o Brasil com os Estados Unidos.

Demonstramos que cenário de um Suriname seguindo uma guinada à esquerda colocaria a América do Sul no centro da contradição Leste-Oeste. Isso atrairia a atenção dos Estados Unidos - que, inclusive, sondou uma ação direta para destituir Bouterse -, e poderia minar a continuidade da estratégia de política externa que vigorava há quase uma década. Os reflexos dessa situação, especialmente no potencial de queda da margem de manobra da política externa brasileira no sistema internacional (e mesmo no cenário regional), bem como dos riscos domésticos que a "cubanização" de um país vizinho representaria, se afiguraram em riscos altos demais para a executiva de política externa. Isso justificou a escolha pela opção da "cooperação com firmeza”, ainda que ela também envolvesse grandes riscos.

Nossa contribuição também realça o potencial do uso da Teoria Prospectiva para os pesquisadores de Análise de Política Externa. Ainda que tenha sofrido questionamentos ao longo das décadas de 1990 e 2000, estudos mais recentes apontam para a sua viabilidade, inclusive para estudos de processo de tomada de decisão que envolva mais de um indivíduo. Com isso, apresentamos uma aplicação da Teoria Prospectiva para um tema pouco estudado pela literatura da política externa brasileira - a Missão Venturini -, um dos principais eventos do período da política externa Universalista, de João Figueiredo (1979-1985).

Observamos que ela é aplicável ao caso, sendo capaz de indicar a sequência de acontecimentos que culminaram na Missão Venturini. Como o Suriname entrava em uma guinada à esquerda em sua política externa, com uma aproximação de Cuba; e despertava a atenção dos Estados Unidos (e o intuito de intervenção deste no governo surinamês); os policymakers brasileiros operavam em viés de perda. Quaisquer decisões em tal cenário seriam arriscadas e suas prospecções de resultados não eram garantidas. A opção por uma intervenção cooperativa, para “cooptar” o Suriname e evitar uma intervenção estadunidense - que colocaria a região no enquadramento Leste/Oeste, limitando o grau de autonomia da política externa brasileira - foi arriscada, visando conter as potenciais perdas do Brasil em relação ao 
observado no status quo ante da crise surinamesa. Entretanto, foi seguida e angariou resultados positivos, reforçando a “opção brasileira” para Bouterse.

\section{Referências}

AVILA, Carlos Federico Domínguez. Guerra Fria na região Amazônica: um estudo da Missão Venturini ao Suriname (1983). Revista Brasileira de Política Internacional. v. 1, n. 54, p. 7-28, 2011.

BEREJIKIAN, Jeffrey. Model building with Prospect Theory: a cognitive approach to International Relations. Political Psychology. v. 23, n. 4, p. 759-786, 2002.

BOETTCHER, William A. The prospects for Prospect Theory: an empirical evaluation of International Relations applications of Framing and Loss Aversion. Political Psychology. v. 25, n. 3, p. 331-362, 2004.

BRASIL. Informação 099 ao Presidente, em 04 mar 1976. Arquivo Azeredo da Silveira, pasta AAS mre ai 1977.03.02. CPDOC/FGV.

BRASIL. Informação 285 ao Presidente, 08 set 1982.1982a. Arquivo Saraiva Guerreiro. Pasta SG mre 1979.03.20, Encadernado volume 05/1982. CPDOC/FGV

BRASIL. Informação 396 ao Presidente, 27 dez 1982. 1982b. Arquivo Saraiva Guerreiro. Pasta SG mre 1979.03.20, Encadernado volume 06/1982. CPDOC/FGV

BRASIL. Informação 019 ao Presidente, 18 jan 1983. 1983a. Arquivo Saraiva Guerreiro. Pasta SG mre 1979.03.20, Encadernado volume 01/1983. CPDOC/FGV

BRASIL. Circtel no 12.691. Secreto-urgente, do Ministério das Relações Exteriores para a Embaixada em Washington. Brasília, 21 jan 1983. 1983b. Arquivo Azeredo da Silveira. Pasta AAS ew 1983.01.20. CPDOC/FGV.

BRASIL. Telegrama no 235. Secreto-Exclusivo-Urgente, da Embaixada em Washington (Antônio Azeredo da Silveira) para o Ministério das Relações Exteriores. Washington, 24 jan 1983. 1983c. Arquivo Azeredo da Silveira. Pasta AAS ew 1983.01.20. CPDOC/FGV.

BRASIL. Telegrama n 236 (resposta). Secreto-Exclusivo-Urgentíssimo, do Ministério das Relações Exteriores para a Embaixada em Washington. Brasília, 26 jan 1983. 1983d. Arquivo Azeredo da Silveira. Pasta AAS ew 1983.01.20. CPDOC/FGV.

BRASIL. Telegrama no 165 . Confidencial, do Ministério das Relações Exteriores para a Embaixada em Washington. Retransmissão do Telegrama no 85, recebido da Embaixada em Paramaribo em 08 fev 1983. Brasília, 10 fev 1983. $1983 \mathrm{e}$. Arquivo Azeredo da Silveira. Pasta AAS ew 1983.01.20. CPDOC/FGV.

BRASIL. Telegrama no 229. Secreto, do Ministério das Relações Exteriores para a Embaixada em Washington. Retransmissão do Telegrama no 118, recebido da Embaixada em Paramaribo em 22 fev 1983. Brasília, 24 fev $1983.1983 f$. Arquivo Azeredo da Silveira. Pasta AAS ew 1983.01.20. CPDOC/FGV.

BRASIL. Telegrama no 501. Secreto-Exclusivo-Urgentíssimo, do Ministério das Relações Exteriores para a Embaixada em Washington. Transmissão do texto da carta de Ronald Reagan para João Figueiredo, de 28 mar 1983. Brasília, 15 abr 1983. 1983g. Arquivo Azeredo da Silveira. Pasta AAS ew 1983.01.20. CPDOC/FGV.

BRASIL. Telegrama no 502. Secreto-Exclusivo-Urgentíssimo, do Ministério das Relações Exteriores para a Embaixada em Washington. Transmissão do texto da carta de resposta de João Figueiredo para Ronald Reagan. Brasília, 15.abr 1983. 1983h. Arquivo Azeredo da Silveira. Pasta AAS ew 1983.01.20. CPDOC/FGV.

BRASIL. Informação 135 ao Presidente, 09 mai 1983. 1983i. Arquivo Saraiva Guerreiro. Pasta SG mre 1979.03.20, Encadernado volume 02/1983. CPDOC/FGV

BRASIL. Informação 254 ao Presidente, 20 set 1983. 1983j. Arquivo Saraiva Guerreiro. Pasta SG mre 1979.03.20, Encadernado volume 03/1983. CPDOC/FGV

BRASIL. Informação 258 ao Presidente, 23 set 1983. 1983k. Arquivo Saraiva Guerreiro. Pasta SG mre 1979.03.20, Encadernado volume 03/1983. CPDOC/FGV 
CAVLAK, Iuri. O Golpe Militar no Suriname e a Geopolítica no Platô das Guianas. Revista de Geopolítica. v. 7, n. 1, p. 133$151,2016$.

FARNHAM, Barbara. Roosevelt and the Munich Crisis: Insights from prospect Theory. In: FARNHAM, Barbara (ed.). Avoiding Losses / Taking Risks: Prospect Theory and International Conflict. Cap 4, p. 41-72. Ann Arbor: The University of Michigan Press, 1994.

GUERREIRO, Ramiro Saraiva. Ramiro Saraiva Guerreiro (depoimento, 1985/1991). Rio de Janeiro: FGV/CPDOC, 2019.

HAAS, Mark. Prospect theory and the Cuban missile crisis. International Studies Quarterly v. 45, n. 2, p. 241-270, 2001.

HOEFTE, Rosemarijn. Suriname in the Long Twentieth Century: Domination, Contestation, Globalization. Nova Iorque: Palgrave Macmillan, 2014.

JANSSEN, Roger. In Search of a Path: an analysis of the foreign policy of Suriname from 1975 to 1991. Leiden: KITLV Press, 2011.

JERVIS, Robert. Political Implications of Loss Aversion. In: FARNHAM, Barbara (ed.). Avoiding Losses / Taking Risks: Prospect Theory and International Conflict. Cap. 3, p. 23-40. Ann Arbor: The University of Michigan Press, 1994.

KAHNEMAN, Daniel; TVERSKY, Amos. Prospect theory: an analysis of decision under risk. Econometrica. v. 47, n. 2, p. 263-291, 1979.

LAMPREIA, Luiz Felipe. O Brasil e os ventos do mundo: memórias de cinco décadas na cena internacional. Rio de Janeiro: Objetiva, 2010.

LEVY, Jack. Prospect Theory, Rational Choice and International Relations. International Studies Quarterly, v. 41, n. 1, p. 87-112, 1997.

LEVY, Jack. Prospect Theory and International Relations: theoretical applications and analytical problems. In: FARNHAM, Barbara (ed.). Avoiding Losses / Taking Risks: Prospect Theory and International Conflict. Cap. 7, p. 119-146. Ann Arbor: The University of Michigan Press, 1994.

MCDERMOTT, Rose. Prospect Theory in International Relations: the Iranian hostage rescue mission. In: FARNHAM, Barbara (ed.). Avoiding Losses / Taking Risks: Prospect Theory and International Conflict. Cap. 5, p. 73-100. Ann Arbor: The University of Michigan Press, 1994.

MCDERMOTT, Rose; FOWLER, James; SMIRNOV, Oleg. On the evolutionary origin of Prospect Theory Preferences. Journal of Politics, v. 60, n. 2, p. 335-450, 2008.

MCMAHON, Robert. The Cold War: a very short introduction. Nova Iorque: Oxford University Press, 2003.

MERCER, Jonathan. Prospect Theory and Political Science. Annual Review of Political Science, v. 8, p. 1-21, 2005.

PINHEIRO, Letícia. Foreign policy decision-making under the Geisel government: the President, the Military and the Foreign Ministry. Brasília: Funag, 2013.

SARAIVA, Miriam Gomes. Política externa, política interna e estratégia de desenvolvimento: o projeto de Brasil potên cia emergente (1974 a 1979). Sociedade em Debate. v. 4, n. 1, p. 19-38. 1998.

SARAIVA, Miriam Gomes. Encontros e Desencontros: o lugar da Argentina na política externa brasileira. Belo Horizonte: Fino Traço, 2012

SAMUELSON, William; ZECKHAUSER, Richard. Status quo bias in decision making. Journal of Risk and Uncertainty, v. 1, p. 7-59, 1988.

SCHENONI, Luis; BRANIFF, Sean; BATTAGLINO, Jorge. Was the Malvinas/Falklands a Diversionary War? A ProspectTheory reinterpretation of Argentina's decline. Security Studies, v. 29, n. 1, p. 34-63, 2020.

URT, Joao Nackle. A Lógica da Construção da Confiança: Relações Brasil-Suriname entre 1975 e 1985. Revista Brasileira de Política Internacional. v. 2, n. 53, p.70-87, 2010.

VIS, Barbara. Prospect Theory and political decision making. Political Studies Review. v. 9, n. 3, p. 334-343, 2011. 
Funções de colaboração exercidas Investigação; Supervisão; Escrita (primeira redação); Escrita (revisão e edição);

Informações fornecidas pelos(as) autores(as) de acordo com a Taxonomia de Funções de Colaborador (CRediT) 